\title{
De la partidocracia a la democracia constitucional-ciudadana'
}

\author{
Alberto Arene \\ Asesor de la Rectoría y miembro del Senado Consultivo de la UTEC
}

Introducción

$\mathbf{T}$ odo, absolutamente todo el conflicto y debate actual sobre las resoluciones de naturaleza política de la Sala de lo Constitucional de la Corte Suprema de Justicia* y los golpes desde el Estado contra sus magistrados, así como el debate en torno a la creación de una comisión especial contra el crimen organizado adscrita a la Presidencia de la República y paralela a la Fiscalía, a la elección del nuevo presidente y junta directiva de la Corte de Cuentas de la República y a la elección de los nuevos magistrados del Tribunal Supremo Electoral, son manifestaciones y expresiones, de algo más profundo: del agotamiento del modelo político-institucional de la postguerra y del primer esfuerzo de comenzar a reformarlo, retomando el camino de reconstruir, refundar e impulsar la democracia constitucional en El Salvador. Este camino es liderado por los cuatro magistrados de la Sala de lo Constitucional y el más amplio movimiento de la sociedad civil organizada desde que concluyó la implantación de los Acuerdos de Paz. Sin el talante democrático y alianza de ambos no existirían las controversiales resoluciones, ni conflicto ni golpe alguno, todo seguiría como siempre, dominado, controlado por los intereses especiales, por los corruptos, los impunes y autoritarios de siempre que tienen secuestrada la democracia y las instituciones. Estos tienen respaldo casi total en el parlamento mientas los magistrados democrático-constitucionales y los movimientos cívicos no tienen ninguno.

El problema es más amplio y complejo de lo que el ciudadano común y una buena parte de los analistas parecen darse cuenta, pudiendo identificar tres problemas principales:

1. El sistema de partidos políticos, y particularmente una buena parte del liderazgo de la irreformable partidocracia que controla importantes pedazos de los poderes del Estado y de sus instituciones. Por eso, el sentimiento cada vez más generalizado de pesimismo, incertidumbre e impotencia que se ha apoderado de los salvadoreños en los últimos años. Aunque ahora existe una mayor conciencia ciudadana de la mediocridad, corrupción y falta de talante democrático y modernizador de una buena parte del liderazgo de la irreformable partidocracia.

\footnotetext{
1 Elaborado a partir de siete artículos publicados en la columna semanal de El Mundo bajo el título "El agotamiento del modelo político-institucional de la posguerra y la partidocracia". San Salvador, del 14 de abril al 2 de Junio 2011.

* Ver, nota final 1, Pág. 80
} 
2. La limitada cultura democrática en el país** y particularmente la cultura democrático-constitucional en la ciudadanía en general, y particularmente en el liderazgo académico e intelectual, empresarial, laboral, cívico-político, en los medios de comunicación, en los editorialistas, articulistas y generadores de opinión pública en general. ${ }^{2}$

3. La ausencia de partidos políticos democrático-progresistas y modernos que representen amplios intereses de la ciudadanía con representación en la Asamblea Legislativa y en el Poder Ejecutivo impide o limita el respaldo a la restauración constitucional iniciada por la Sala de lo Constitucional, cuya viabilidad y sostenibilidad requiere una mayoría política y social y un liderazgo de profundas convicciones democráticas en el país.

Después de una breve referencia a las características principales de la transición democrática y del modelo político-institucional de la posguerra incapaz de realizar las reformas para profundizar la democracia y fortalecer la institucionalidad, se analizan la partidocracia y los partidos políticos como el eslabón más débil del sistema democrático, origen último de la debilidad y crisis del sistema democrático-institucional. Luego se analizan los poderes fácticos que tanto influencia ejercen sobre los mismos y la ausencia de liderazgos y partidos democráticos y modernos, pronunciándonos por la calidad de la democracia y por una democracia de ciudadanos. Finalmente, nos preguntamos ¿cómo mejorar la calidad de la democracia con el sistema anacrónico de partidos y liderazgos políticos que tenemos? Y respondemos: a través de tres vías de acción:

1. Denuncia y presión de la sociedad civil y de la opinión pública.
2. Presión y persuasión para reformar los partidos políticos

3. Con nuevos liderazgos y partidos democráticos capaces, eficientes y transformadores.

\section{La transición democrática en Centroamérica y en El Salvador}

En Nicaragua, El Salvador y Guatemala, el nuevo orden democrático fue -literalmente - negociado en el marco de la finalización de los conflictos, iniciándose una transición democrática de naturaleza distinta a aquellas transiciones de la dictadura a la democracia en Estados y sociedades de larga tradición democrática e institucional. Honduras también padeció la dictadura y las consecuencias de las guerras y de las negociaciones de paz de sus vecinos, aunque su propia guerra y fractura le llegó tres décadas después, con el agotamiento del bipartidismo liberal-conservador cada vez más dominado por los poderes fácticos, planteándose ahora el imperativo de la refundación democrático-institucional.

Más allá de la voluntad política de las partes involucradas en la guerra y en la negociación de la paz, la mediación e influencia del Consejo de Seguridad de las Naciones Unidas, a través del Secretario General, posibilitó crear las condiciones y correlación de fuerzas necesarias para firmar e implantar los acuerdos de paz fundacionales de la democracia, apoyando y acompañando el inicio de construcción del Estado democrático salvadoreño. ${ }^{3}$ La democracia ascendente en la etapa de implantación de los acuerdos (1992-1996) fue posible por la obligatoriedad de su cumplimiento bajo la tutela de grandes poderes internacionales. Al concluir su ejecución y quedar el proceso bajo la responsabilidad y soberanía total de los salvadoreños siguieron el estancamiento primero y la

\footnotetext{
2 Ver por ejemplo, Lafitte Fernández, "La Razón, y no el poder, es la nueva moneda”, Opinión, El Mundo, 14.6.11.

${ }^{* *}$ Ver nota final 2, Pág. 80

3 Si bien los primeros pasos para la supeditación del poder militar al poder civil se iniciaron con la Asamblea constituyente de 1982, y la constitución de 1983, la elección y el gobierno de José Napoleón Duarte profundizaron este proceso poniendo los primeros cimientos del futuro régimen democrático
} 
involución después, instalándose desde entonces una democracia de muy baja intensidad e institucionalidad.

La cultura y fuerza democrática y la ciudadanía política y social eran muy débiles frente a los poderes fácticos tradicionales y la partidocracia que se apropiaron del proceso, impidiendo la profundización y consolidación democráticoinstitucional. Este es el caso de El Salvador y -con sus diferencias y particularidades— también del CA-4.

El modelo político-institucional de la postguerra (19912011), iniciado aún antes de los Acuerdos de Paz, que podemos caracterizar de democracia de baja intensidad e institucionalidad dominada por la partidocracia, desarrolló un sistema político-institucional que fue incapaz de realizar las reformas correspondientes para consolidar la democracia y fortalecer la institucionalidad. Tal modelo se centró en la desmilitarización de la sociedad y la supeditación de las Fuerza Armada al poder civil, así como en la garantía formal de los derechos humanos, civiles y políticos. Pero no avanzó en los derechos económicos y sociales, en la promoción y fortalecimiento de la cultura democrática, ni en las reformas que modernizarían el Órgano Judicial, el Ministerio Público, la Corte de Cuentas y el sistema de partidos políticos, cuyo anquilosamiento es el origen de la debilidad institucional que padecemos.

\section{La partidocracia}

Los partidos políticos en El Salvador son el eslabón más débil de la democracia y el origen último de la debilidad del resto de instituciones democráticas. Como es conocido en el análisis de sistemas, un sistema es tan fuerte como lo es su eslabón más débil. Nuestro sistema democrático es muy débil porque son muy débiles nuestros partidos políticos y las instituciones públicas cuyos directores son nombrados por ellos, con los tradicionales poderes fácticos, principalmente económicos, viejos y nuevos, detrás de todos ellos.

La elección de una buena parte de los funcionarios más importantes del Estado las hacen las cúpulas de los partidos políticos, buena parte de los cuales son vanguardia de la ignorancia, la corrupción, el autoritarismo, la falsedad y la mediocridad. Evitar la formación y el debate de ideas y cerrar el partido protegiendo el centímetro cuadrado que controlan es su negocio, pues terror le tienen a que entren y los desplacen gente honesta y capaz.

Pero los partidos políticos son demasiado importantes para dejarles a ellos mismos la suerte de su evolución y destino, afectando los intereses de todos los ciudadanos y el futuro de la nación salvadoreña, bajo la superficial e ingenua premisa que si no se componen el electorado los castigará en la próxima elección. El supuesto Estado democrático y social de derecho y la sociedad civil no tienen injerencia alguna sobre las reglas de juego hacia adentro y hacia afuera con las que operan, profundizando en su seno la ausencia de democracia e institucionalidad interna y la impunidad en las instituciones del Estado. Así han ido pisoteando el sistema democrático-institucional desde que concluyó la primera y única ola de reformas vinculadas a los Acuerdos de Paz (1996), burlándose abiertamente de los ciudadanos a quienes tratan como verdaderos débiles mentales.

Confirmamos periódicamente en las encuestas el sentimiento ciudadano de repudio y los índices más bajos de popularidad hacia los partidos políticos y la Asamblea Legislativa donde trabajan sus principales líderes. Los adultos contemporáneos y mayores lamentamos cada vez más frecuentemente su lamentable desempeño, y los jóvenes no tienen el más mínimo interés por semejante parque jurásico, ignorando, literalmente, su existencia. 
La realidad descrita es conforme con lo que se conoce como partidocracia, citando ampliamente su caracterización:

"Partitocracia o partidocracia se trata de un neologismo empleado para definir la burocracia de los partidos políticos. Según el filósofo Gustavo Bueno "la partitocracia constituye una deformación sistemática de la democracia. Cada partido tiene sistemáticamente que atacar al otro". Asimismo, para la teoría antiliberal, "la partitocracia es aquella forma de Estado en que las oligarquías partidistas asumen la soberanía efectiva", como lo enunció Gonzalo Fernández de la Mora, (Calero, 1982, p.54). Su desarrollo suele venir aparejado con los sistemas parlamentarios.

"Es un término que se utiliza para designar el sistema de gobierno en el cual, aunque teóricamente se vive en democracia, los actores principales y únicos del panorama político son los grandes partidos políticos. Estos, a base de un sistema democrático de turnismo, se van pasando el gobierno de forma consecutiva, coartando las posibilidades de que los ciudadanos expresen su voluntad real más allá de los partidos ya existentes. Partiendo de la base de que los partidos son un mal necesario, los ciudadanos se van apartando de ellos y buscan otros cauces para intervenir, lo que lleva a la creación de los llamados grupos de presión. En muchas ocasiones también viene asociado a sistemas bipartidistas.

"La idea de democracia y sus iníciales puestas en práctica, se ubican con anterioridad al aparecimiento de los partidos políticos. Las primeras experiencias de regímenes democráticos en la Grecia Antigua y aún en la República Romana poco tenían que ver con lo que hoy llamamos partidos políticos. Sin embargo, en la democracia moderna, el concepto y práctica del partido político no solo aparece como pieza indispensable del aparataje político sino que, con el desarrollo de los regímenes democráticos, el papel de los partidos políticos se ha ido volviendo de tal manera central que en algunas concepciones del Estado moderno llega a sustituir la caracterización del Estado como democrático, para convertirlo en "Estado de partidos".

"La concepción del Estado democrático, tanto en su versión de democracia representativa como de la directa, se asienta sobre una relación bilateral entre ciudadanos y Estado. Tal y como la conocemos hoy, la naturaleza de la democracia estriba en la apropiación por parte del pueblo del poder político; y de ahí surge la necesidad de nombrar representantes para que, proviniendo de y a nombre del pueblo, le administren su original poder. Sin embargo, en la práctica histórica, esta relación bilateral pasa a adquirir crecientemente un carácter trilateral: ciudadano-partido político-Estado, de tal manera que el ejercicio de la soberanía popular ya solo es posible mediante la mediación de los partidos. "En el diseño de la democracia representativa, los partidos políticos ocupan un lugar secundario e instrumental, siendo su principal función la de constituirse como uno de los vehículos que facilitan al ciudadano-elector escoger a sus representantes; sin embargo, con el desarrollo de la democracia y la creciente complejidad de las sociedades modernas, este papel tiende a modificarse sustancialmente. Primeramente porque, ya sea de hecho o por ley, los partidos van apropiándose el monopolio de esa instrumentalidad y en la práctica se convierten en el único vehículo para acceder a la representación del pueblo en los órganos del Estado. En segundo lugar, porque los partidos prolongan en el tiempo su papel, $y$, de instrumentos del mecanismo electoral, pasan a asumir un creciente control sobre el ejercicio de la representación popular, sometiendo a los representantes del pueblo a la disciplina partidaria. En la práctica, la concepción del "mandato libre" tan cara no solo a los pioneros de la democracia, sino a muchos exponentes contemporáneos de la sociedad civil, ha quedado anulada. 
"Y finalmente, los temas sustantivos del quehacer político pasan a ser definidos, asumidos y resueltos por los partidos políticos. Los órganos del Estado como lugares del ejercicio de la representación, tienden a vaciarse de contenido y el Parlamento queda redefinido para utilizar el dictum de Leibholz, como el lugar en el que 'se reúnen comisionados de partidos vinculados a las decisiones de éste, para dejar constancia de decisiones ya adoptadas en otros ámbitos (en comités y congresos de partido).' Es evidente que aquí ya no se trata de un Estado democrático, sino de un Estado de partidos. ${ }^{4 \prime \prime}$

Como lo afirmó un ciudadano que participa activamente en una de las nuevas redes sociales surgidas recientemente, al referirse a la crisis del Estado de derecho y de la institucionalidad democrática:

"En lo fundamental, esta crisis tiene que ver con la forma en que los partidos políticos se reparten las instancias de poder. Desde julio de 2010, los magistrados de la Sala de lo Constitucional han dictado sentencias que van en contra de ese modo tradicional de actuar. Si los partidos violaron la ley al decidir por decreto que siguieran existiendo el PCN y el $P D C$, la Sala resolvió que se cumpla la ley y abrió la puerta a la cancelación de ambos. Si los diputados le deben más fidelidad al partido que al pueblo, la Sala ha dicho que se puede aspirar a ser diputado sin pertenecer a ningún partido. Si los partidos son los que deciden quién puede ser diputado, la Sala ha mandado que sea la ciudadanía la que decida quién es su representante votando directamente por el candidato de su preferencia. Si los diputados eligieron a sendos representantes del PCN y PDC para magistrados del Tribunal Supremo Electoral, la Sala mandó la destitución de esas personas para que se cumpla la ley". ${ }^{5}$
Efectivamente, se trata de la reacción de la partidocracia al primer intento, después de finalizada la implantación de los Acuerdos de Paz (1996), de comenzar a desarrollar la democracia constitucional en El Salvador.

\section{La necesidad de transformar el sistema de partidos políticos}

Pero ha llegado el momento de analizar y confrontar seriamente la problemática de los partidos políticos cada vez más estudiada internacionalmente. ${ }^{6}$

Según Thomas Carothers, uno de los principales expertos mundiales sobre partidos políticos, el "lamento estándar" sobre los partidos es el siguiente:

- "Los partidos son organizaciones corruptas y de intereses privados, dominados por elites hambrientas de poder que solo persiguen sus propios intereses o de los financistas ricos que los apoyan, no el de los ciudadanos ordinarios."

- "Los partidos no creen en nada; no hay diferencias reales entre ellos. Sus ideologías son simbólicas, en el mejor de los casos, y sus plataformas son vagas o insustanciales."

- "Los partidos pierden demasiado tiempo peleando entre sí sobre pequeños temas hacia fines de ventajas políticas sin sentido, en lugar de tratar de de resolver los problemas del país de una manera constructiva y cooperativa."

- "Los partidos solo se vuelven activos en tiempos de elecciones cuando Ilegan buscando tu voto; el resto del tiempo nunca oyes de ellos."

4 PARTIDOCRACIA (http://es. wikipedia.org/wiki/Partitocracia)

5 Henry Fauno, "Despierta, El Salvador, ya," 13 de junio, 2011.

6 Ver, por ejemplo, Thomas Carothers, "Confrontando el vínculo más débil. Ayudando a los partidos políticos en las nuevas democracias". Carnegie Endowment for International Peace. Washington D.C., 2006. 
- “Los partidos están mal preparados para gobernar el país y hacen un mal trabajo cuando logran tomar el poder o ganan lugares en la legislatura nacional." Carothers concluye: "En diferentes países se oyen a veces puntos adicionales de condena sobre sus partidos, enfatizando temas que pueden ser particulares a esa escena política, como un líder de partido conocido por un mal comportamiento especialmente flagrante, colusión entre la oposición y el partido gobernante, o haber éste hecho trampa en la última elección. El lamento estándar es una narrativa común central en casi todas las nuevas democracias en lucha, pero no necesariamente siempre la historia completa de la infelicidad del público con los partidos".7

Las principales reformas que deben impulsarse ya están identificadas, comenzando con la transformación del sistema electoral y del sistema de partidos mediante las reformas e implantación de leyes que aseguren su democracia e institucionalidad interna, el control de sus fuentes de financiamiento, la formación de sus militantes y dirigentes para actualizar su visión del país y del mundo, así como su preparación para ejercer la función pública. Además, deberá cumplirse con la resolución de la Sala de lo Constitucional sobre las candidaturas no partidarias y el sistema de listas abiertas. El Tribunal Supremo Electoral deberá estar conformado por magistrados capaces e independientes de los partidos políticos.

Pero ¿cómo podemos esperar que los partidos políticos se reformen a sí mismos afectando sus particulares maneras de pensar y actuar, los mecanismos de reproducción de su poder interno y externo, sus diversos privilegios y los intereses principales que los animan?
Los partidos políticos desempeñan cuatro funciones centrales en las democracias modernas: 1. Representar a los ciudadanos/votantes en el Estado; 2. Desarrollar políticas y programas gubernamentales coherentes y canalizar las demandas sociales; 3. Buscar, seleccionar y capacitar candidatos para ocupar cargos en los distintos niveles de gobierno y legislaturas, y 4 . Hacer seguimiento al desempeño del gobierno de turno y desplegar labores de oposición, generando alternativas.

Mientras no se invente otra manera más democrática y efectiva de asumir las funciones que desempeñan -mal, regular o bien-, los partidos políticos seguirán teniendo un papel fundamental en el devenir económico, social y político-institucional de las naciones. Como lo afirma la idea internacional, si bien se ha escrito mucho sobre las deficiencias evidentes de los partidos políticos, ningún otro actor podrá reemplazarlos. En algunos países, los políticos crean movimientos que supuestamente se diferencian de los partidos políticos por ser fuerzas de unión que representan a toda la sociedad y no sólo a un segmento. Sin embargo, en la mayoría de los casos, el movimiento termina siendo simplemente un término que reemplaza las desprestigiadas palabras "partido político".

Tres décadas después de iniciada la llamada Tercera ola democrática, la modernización, transformación y fortalecimiento de los partidos políticos en Latinoamérica está progresivamente en el centro de la reflexión y discusión de los grandes institutos y pensadores políticos, y de gobiernos y agencias bilaterales y multilaterales de cooperación internacional. Es parte de un debate más amplio sobre el imperativo de profundizar y consolidar el sistema democrático-

\footnotetext{
7 Thomas Carothers, OP. CIT.
} 
institucional de Latinoamérica, siendo Centroamérica parte importante de los estudios realizados. ${ }^{8}$

En las últimas dos décadas, varios factores han acelerado el interés por la gobernabilidad democrática y los partidos políticos en Centroamérica: 1. La existencia de democracias de baja intensidad con limitada institucionalidad y ciudadanía política y social en la subregión más desigual del mundo; 2. La penetración del narcotráfico en varios Estados, instituciones públicas y partidos políticos; 3 . El control o influencia decisiva en varios partidos políticos conservadores de poderes fácticos empresariales y mediáticos; 4. El llamado "Socialismo del siglo XXI" y los avances en la construcción e impulso del eje del Alba en Sur y Centroamérica, el apoyo político y financiero del presidente Chávez al presidente Ortega, en Nicaragua, y sus consecuencias en la concentración del poder y el retroceso democrático-institucional, aunado al involucramiento de Chávez en Honduras 5. El intento de golpe desde el Estado liderado por Zelaya en Honduras, aprovechado por el establecimiento político hondureño para perpetrar el golpe de Estado que fracturó al país y lo aisló internacionalmente, y 6. El apoyo político y financiero de Chávez al FMLN, de El Salvador, primera fuerza política y principal partido en el Gobierno, generando grandes preocupaciones e incertidumbres.

\section{Los poderes fácticos}

El tema del control o influencia decisiva de los poderes fácticos en las democracias latinoamericanas es de primera importancia. Analizando el proceso de toma de decisiones en el sistema político, Cortez Terzi dijo: "Una serie de indicadores muestran que el sistema democrático en Chile y en América Latina si bien, como nunca antes, se encuen- tra protegido por amplios consensos políticos y por los escenarios internacionales, está afectado por una tendencia que socava su legitimidad y funcionalidad. ... tal fenómeno consiste en que el proceso de toma de decisiones tiende a desinstitucionalizarse o informalizarse $y$, a la par, a tornarse desconocido y misterioso, no solo para la ciudadanía, sino también para muchos de los actores incluidos en los circuitos formales del proceso... fenómeno conocido como el circuito extrainstitucional del poder". Agregando que, "Dos grandes hechos explicarían el agotamiento del sistema tradicional de toma de decisiones como la aparición del fenómeno en referencia: 1. Las transformaciones profundas que afectaron la figura estatal: el abandono o debilitamiento de funciones económico-productivas, económico-reguladoras e intervencionistas y de funciones sociales de parte del Estado... La institucionalidad tenía como respaldo fáctico el poderío económico del Estado; los partidos disponían de fuerzas merced al clientelismo posible, gracias a ese tipo de Estado; los parlamentarios eran gestores de demandas sociales ante el Estado, etc. Sin la pervivencia de ese modelo de Estado, la institucionalidad y las instancias políticas perdieron poder factual $y$, con menos capacidad factual, perdieron también poder formal y prestigio, que es fuente legitimadora de poder; y 2. El fortalecimiento acelerado y en crecimiento de dos poderes factuales: la gran empresa privada y los medios de comunicación masivos, en especial, los televisivos". El Estado no está en las mismas condiciones de antaño para integrar arbitrariamente a la institucionalidad -y de manera subordinada - a los poderes factuales".9

En la época que vivimos, de manera frecuente si no generalizada, los partidos y sus líderes terminan generalmente respondiendo más a los poderes fácticos dentro del circuito extrainstitucional del poder que a los electores que los eli-

8 Ver, por ejemplo, "Un desafío a la democracia: los partidos políticos en Centroamérica, Panamá y República Dominicana." Diego Achard y Luis González, BID, IDEA, OEA, PNUD, San José, Costa Rica, 2004.

9 Cortez Terzi, Antonio. El circuito extrainstitucional del poder, Ediciones Chileamerica CESOC, Chile 2000. 
gieron, cuyos votos a su vez están muchas veces influenciados por campañas financiadas por dichos poderes fácticos. Si esto es cierto en Chile y en Costa Rica, lo es aún más en el resto de Centroamérica, que inició su vida democrática en las últimas dos décadas.

\section{La ausencia de liderazgos y partidos políticos demo-} cráticos y modernos

Buena parte del origen del estancamiento e involución en la construcción democrático-institucional de nuestros países se encuentra en la ausencia de liderazgos y de partidos democráticos y modernos. La democracia no es posible sin demócratas convencidos y organizados, con visiones compartidas, estrategias coherentes y prácticas eficientes. Desde una perspectiva democrática, el primer gran criterio de análisis y la primera gran pregunta no es quién es de izquierda o derecha, sino quién tiene un pensamiento y una práctica democrática coherente y eficiente y quién no. ¿Ser o no ser demócrata capaz? Esa es la pregunta y el desafío.

Una característica muy peculiar y generalizada en buena parte de los dirigentes políticos es responder afirmativamente esta pregunta respecto a sí mismos, identificando y señalando siempre el problema en los demás. Esto es igualmente válido respecto a visiones y prácticas muy atrasadas y generalizadas en los partidos políticos: 10

1. Comportamiento autoritario, centralista y concentrador de poder. La autoridad legítima se ejerce autoritariamente. La decisión tiende a concentrarse en el líder del grupo, quien centraliza la información y controla las decisiones, generalmente excluyentes.
2. Propiedad privada de la práctica política, el yo, yo, yo y el individualismo en el manejo de las relaciones, de la información, en la toma de decisiones, en la falta de trabajo en equipo, en declaraciones públicas.

3. Comportamiento antidemocrático, falta de transparencia e irrespeto de la institucionalidad interna.

4. Falta de formación y actualización de la visión de país y propuesta programática. Se lee muy poco, no existe actualización sobre temas o informaciones básicas, menos aún complejos.

5. Excesivo involucramiento emocional e irrespeto a las opiniones divergentes que dificulta el logro de acuerdos que dependen más de la calidad de la relación personal y del manejo y afinidad emocional, que de la importancia y dominio del tema.

6. Falta de administración, gestión y planificación del tiempo personal, del de grupo, y de los procesos electorales o de desarrollo partidario (puntualidad, asistencia, agendas, programa de trabajo, etc.). No existe concepción del recurso tiempo. La impuntualidad y el incumplimiento se consideran conductas normales. No hay noción de la urgencia.

7. Bajo acatamiento a las normas y procedimientos (indisciplina, impuntualidad, incumplimiento de agendas y compromisos).

8. Falta de motivación y compromiso con iniciativas y procesos orientados al logro de resultados.

9. Tendencia predominante de culpar a terceros de la situación propia, de su grupo y/o de su partido, mecanismo para eludir la responsabilidad propia.

\footnotetext{
10 Este diagnóstico se basa, parcialmente, en el trabajo y sistematización realizados por la Dra. Mireya Rodríguez después de 7 años de talleres participativos con partidos políticos en Venezuela, Centroamérica y el Caribe, recogidos en varios documentos. Ver, entre otros, "Propuesta para un nuevo enfoque complementario en la transformación de los partidos políticos y de su liderazgo". Caracas-Tegucigalpa. Mimeo.
} 
10. Priorización de la amistad en las relaciones políticas soliéndose recurrir a descalificación cuando no se es amigo o no se es parte del mismo grupo.

11. Predominio de una visión parcial y fragmentaria de la realidad, donde prevalece un enfoque cortoplacista, que busca soluciones fáciles e inmediatas a problemas complejos de larga data.

12. Bajo nivel de reflexión y desconocimiento del contexto, con una ausencia sistemática de análisis históricos y de entornos partidarios, municipales, sectoriales, departamentales, nacionales e internacionales.

13. Excesiva concentración de esfuerzos en el logro de intereses personales, donde solo es válida la "verdad" que maneja cada quien.

14. Poca o ninguna planificación del trabajo, no se establecen objetivos ni se jerarquizan las prioridades, no existe método ni sistematización del trabajo individual y colectivo.

15. No se elaboran estrategias, ni planes de trabajo para guiar y organizar la acción política a todos los niveles. Tendencia a la improvisación frecuente, que traduce pérdida de recursos y oportunidades.

16. Dificultades para trabajar en equipo y delegar. No existe la práctica formal de transmitir información y compartir análisis diversos con compañeros(as) de Partido. No se debate con quienes se tienen distintas visiones y convicciones, traduciéndose en la imposición de una sola perspectiva en el análisis de los hechos políticos.

17. Altos niveles de desconfianza que impiden la comunicación interna. Predomina la comunicación informal, que alimenta el manejo de rumores.
18. Ausencia de métodos eficientes de trabajo. No se preparan los temas para las reuniones de trabajo, por lo que existe bajo nivel de argumentación y se suelen extender demasiado en una explicación. Falta de documentación de las reuniones y de los acuerdos, no se manejan las agendas personales ni de trabajo. No es frecuente el uso de minutas, ni actas sobre los acuerdos, ni formatos para el seguimiento de las tareas asignadas.

19. Poca relevancia al cumplimiento de objetivos, al seguimiento y a la evaluación. El establecimiento de controles y evaluaciones genera incomodidad y rechazo.

20. Se responde a poderes que están fuera de la institucionalidad partidaria.

Como se afirma en el trabajo citado: "Hasta el momento, estos factores han disminuido la motivación para el trabajo partidario, obstaculizando o retardando las soluciones identificadas, promoviendo la improductividad, causando la deserción de quienes tienen conductas distintas o buscan salidas alternativas para sus partidos y comunidades. En la práctica, estas conductas del liderazgo se han traducido en pérdida de oportunidades, dispersión de iniciativas, despilfarro de recursos, insatisfacción generalizada, aislamiento frente al progreso y postergación permanente de los cambios personales, grupales e institucionales que permitirían a estas organizaciones fortalecerse frente a su adversario, reconectarse con su electorado y reposicionarse en la sociedad".

"Nuestra experiencia nos ha demostrado que este comportamiento basado en negativas creencias y disfuncionales formas de trabajo, impacta negativamente el funcionamiento y la productividad del liderazgo político y se convierte en una fuerte limitación para cualquier tarea transformadora 
de las organizaciones políticas. Estas prácticas culturalmente muy profundas y arraigadas se reproducen - en mayor o menor grado- en el resto de los países de la región y su superación - a nuestro juicio-constituye el problema principal a resolver, como requisito indispensable para asegurar el éxito de los esfuerzos de modernización partidaria que hasta ahora se han venido conduciendo."11

\section{Hacia una Democracia de Ciudadanos}

Daniel Zovatto, director regional para América Latina y el Caribe de IDEA Internacional, principal organizador del II Foro Internacional Santo Domingo, celebrado la tercera semana de mayo 2011 -al que asistieron medio centenar de los mejores expertos en América Latina sobre el estado de la democracia - asegura: "El problema ya no es sí democracia si o democracia no, sino la calidad de esta democracia...". "El debate en nuestros días no es, como en el pasado, entre democracia o autoritarismo o bien entre democracia formal y democracia real. El debate de nuestros días se concentra, por el contrario, en la calidad de la democracia; en cómo construir más y mejor ciudadanía; en cómo pasar de una democracia electoral a una de ciudadanos y de instituciones; en cómo conciliar democracia con desarrollo en el marco de sociedades con mayores niveles de cohesión social y mayor equidad de género; en cómo buscar una relación más estratégica entre el mercado y el Estado y una más funcional entre Estado y sociedad; en cómo lograr que la democracia dé respuestas a nuevos tipos de demandas provenientes de sociedades más complejas, más modernas, más urbanas; en cómo hacer funcionar de manera eficaz la democracia en un contexto internacional globalizado. Temas todos ellos que, como se puede observar, constituyen problemas de la democracia que deben discutirse en democracia, y cuya solución debe encontrarse de manera democrática." Y hablando de desafíos y retos, destacó: "Los problemas institucionales que afectan la gobernabilidad y el Estado de derecho, la independencia y la relación entre los poderes, la corrupción, el funcionamiento de los sistemas electorales y del sistema de partidos políticos, así como los graves problemas de inseguridad ciudadana... el reto principal reside no sólo por ser electo democráticamente sino también por la necesidad de gobernar de manera democrática. Es imperativo mejorar la calidad institucional, complementándola con liderazgos responsables, tanto desde el gobierno como desde la oposición. El hiperpresidencialismo, el fenómeno creciente de la reelección y de la personalización del poder, la relación del dinero con la política -incluido el tema de la penetración del dinero del narcotráfico y del crimen organizado-, la compleja aunque vital relación entre medios de comunicación y poder político, así como el peligro de los 'golpes desde el Estado', son algunos de los temas prioritarios que demandan nuestra atención".12

Hacia un Estado de y para la democracia en América Latina es el título de la publicación que recoge la más profunda y actualizada reflexión sobre la democracia en el continente ${ }^{13}$ que rebasa, de lejos, el objeto más limitado de este artículo. En esta perspectiva más amplia se sitúa el desafío de restaurar, más bien, fundar y desarrollar la democracia constitucional en El Salvador y Centroamérica, lo que conlleva la implantación progresiva de una nueva cultura democráticoconstitucional en nuestro país y subregión.

Pero dichos desafíos nos remiten a una pregunta muy concreta y de gran actualidad: ¿cómo mejorar la calidad de la democracia con el sistema anacrónico de partidos y liderazgos políticos que tenemos?

\footnotetext{
11 Mireya Rodríguez, Op. Cit. Pgs. 2-3

12 Infolatam, 11.5.11

13 PNUD, OEA, Unión Europea, "Democracia/Estado/Ciudadanía. Hacia un Estado de y para la democracia en América Latina". Mirza Editores e Impresores. Lima, Perú. Febrero 2008. P-www.undp.org
} 
VII. ¿Cómo mejorar la calidad de la democracia con el sistema anacrónico de partidos y liderazgos políticos?

La respuesta no es destruir el sistema de partidos políticos para favorecer la llegada al poder de los antiguos dictadores militares del siglo pasado, confrontados por las fuerzas democráticas y progresistas a lo largo del sangriento siglo XX. Pero tampoco es destruir el sistema de partidos políticos para favorecer a los nuevos líderes mesiánicos del siglo XXI, encantadores de serpientes que se aprovechan de las frágiles democracias dominadas por elites económicas y políticas corruptas para llegar al poder y desde ahí dar el golpe desde el Estado, concentrar todos los poderes e impulsar los populismos Ilamados hoy socialismo del nuevo siglo, liderados por impecables estrategas de la confrontación y división nacional, de la corrupción y del empobrecimiento sostenible de sus pueblos.

La respuesta es: 1. Con buena información, análisis, monitoreo, denuncia y presión de la sociedad civil y de la opinión pública. 2. Con presión y persuasión permanente para reformar los partidos políticos, yendo a su encuentro con iniciativas, metodologías y herramientas diversas. 3. Con la promoción y apoyo a nuevos partidos y liderazgos democráticos capaces, eficientes y transformadores.

\section{El papel de la sociedad civil y de la opinión pública}

Con buena información, análisis, monitoreo, denuncia y presión, la sociedad civil y la opinión pública constituyen el factor fundamental para mejorar la calidad de la democracia frente al sistema anacrónico de partidos y liderazgos políticos que tenemos. Entre más amplia, plural, organizada y movilizada esté la sociedad civil y más cercana a los diversos medios de comunicación social, mejor y mayor será su presencia en la opinión pública, y mayor será su impacto. Pero esto no solo debe servir para evitar y denunciar abusos y exigir derechos, sino para transformar la cultura política y el anacrónico sistema de partidos y liderazgos políticos que tenemos.

¿Conocen, investigan, informan y denuncian los líderes de la sociedad civil, los generadores de opinión pública y los periodistas las prácticas comunes de varios partidos políticos? Mencionemos algunas de las más comunes:

1. Inscripción y registro al partido de personas sin ninguna idoneidad, sin preparación y formación previa, con el propósito, de uno de los grupos, de fortalecer su correlación de fuerzas frente a otros grupos a los que se quiere debilitar o derrotar;

2. Depuración de personas del grupo contrario en los mal llamados tribunales "de honor", sin debido proceso, con el objeto de penalizar comportamientos contrarios al poder y fortalecer su control y dominio;

3. Falta de penalización de la corrupción, la mediocridad y la incapacidad del "máximo líder", de sus colaboradores principales, o de los responsables de las distintas secretarías partidarias;

4. Toma de decisiones y/o declaraciones públicas del líder nacional, departamental o local que no han sido discutidas, consensuadas o aprobadas en los órganos respectivos;

5. "Caciques" partidarios que reciben dinero de empresarios, comerciantes o del platudo de turno, vendiendo leyes o favores nacionales o municipales sin que nadie se entere, hipotecando la independencia de su partido y de los mismos ciudadanos votantes;

6. Venta del "líder"o "cacique" partidario local o nacional a otros partidos de las credenciales partidarias en tiem- 
pos de elecciones, o promesas a algunos de sus allegados de repartirles parte de la deuda política a cambio de votar por ellos en las elecciones internas;

7. Manejo de la información, de las relaciones y las decisiones fundamentales en un grupúsculo cerrado de gentes, actuando de forma centralizada, y como que si el partido les perteneciera privadamente;

8. Ausencia de formación y capacitación de dirigentes y militantes;

9. Promoción y elección de personas deshonestas e incapaces a puestos de dirección o a candidaturas por la argolla que detenta el poder, $\mathrm{y}$

10. Diputados o alcaldes que, sin ninguna consulta a las instancias de decisión partidaria, contratan, con dinero público, a allegados en puestos, fantasmas o reales, a veces sin calificación técnica, para fortalecer sus personales estructuras de poder en su municipio, departamento $\mathrm{y} / \mathrm{o}$ en el partido.

Estas prácticas comunes violan todos los días las normas más básicas de la democracia, la transparencia y la institucionalidad interna, sin que pase nada adentro o afuera de los partidos, con la más absoluta impunidad, violando las leyes y reglamentos que gobiernan al partido y al país.

A pesar de que los partidos políticos son las instituciones públicas que más afectan la vida de los ciudadanos, son las menos democráticas, transparentes y eficientes, y las más autoritarias, impunes e ineficientes. ¿Por qué? Por dos razones fundamentales: 1 . Tienen poder y capacidad coercitiva en los poderes Ejecutivo, Legislativo, Judicial, en la Fiscalía, en la Corte de Cuentas y en las municipalidades, pudiendo siempre "joder" a alguien. 2. Ni la sociedad civil, ni los medios de comunicación, ni el Estado, se ocupan de ellos, permitiéndoles que actúen con el mayor libertinaje y la más descarada impunidad.

La llamada sociedad civil conoce poco a los partidos, no se les da seguimiento, nos hemos desentendido de ellos, cada vez nos disgustan y decepcionan más, adoptando la misma actitud de desprecio y rechazo que tienen los jóvenes con ellos, y hasta su misma expresión lo demuestra: ¡Guácala...!

Hacia los partidos políticos actuamos más con el hígado y las emociones que con el conocimiento, el análisis y la estrategia para incidir en ellos y mejorarlos. Hace ratos la ciudadanía los declaró "detestables" y, en el mejor de los casos, una especie de "mal necesario" sobre los cuales nada podemos hacer, profundizándose un sentimiento combinado de frustración y eterna resignación. ¿Impotencia, cobardía, nos rendimos y les agachamos la cabeza?

En lo que concierne al Estado -el Tribunal Supremo Electoral - tampoco los fiscaliza, porque esa institución está partidizada, sus magistrados son puestos ahí por los partidos políticos, los representan y velan por sus intereses. El TSE está secuestrado por los partidos políticos, aunque hayan magistrados más honestos, responsables, capaces e institucionales que otros.

Los liderazgos de la sociedad civil organizada y los columnistas, editorialistas y los(as) generadores de opinión, los periodistas, editores(as) y los jefes de redacción necesitan mayor formación, información y análisis sobre el funcionamiento de los partidos políticos y sobre sus principales líderes para poder ejercer su labor de análisis, monitoreo, y denuncia. Necesitamos periodistas profesionales bien formados en política, partidos políticos y tribunales electorales. Ellos más que nadie deberían ser los ojos y oídos de la sociedad. 
Para ello deben conocer los estatutos de los partidos y su cumplimiento en la práctica, desde lo que atañe a su democracia e institucionalidad interna (elección de sus autoridades y órganos de representación y conducción, representantes ante el tribunal electoral, y candidatos), a su apertura externa (relaciones, interlocución e incorporación de otros sectores de la sociedad) y a su transparencia informativa y financiera y a la rendición de cuentas (montos, fuentes, utilización, auditorías), pasando por la formación permanente de sus dirigentes y militantes, la participación efectiva de jóvenes y mujeres, los mecanismos de monitoreo y evaluación de su actividad y comportamiento, y el proceso objetivo y justo de sanciones en las instancias correspondientes. Y deben disponer del mayor y mejor acceso e información interna posible.

\section{La reforma de los partidos y liderazgos políticos}

El papel de la sociedad civil para evitar y denunciar abusos, exigir derechos y transformar la cultura política es crucial, pero no basta. Es imperativo reformar el sistema de partidos y liderazgos políticos yendo a su encuentro con iniciativas, metodologías y herramientas diversas.

Se necesita transformar los partidos políticos con un enfoque práctico que los haga descubrir que la renovación es buena política, que al asumirla lograrán más votos, diputados, alcaldes y concejales, contribuirán a desarrollar mejores instituciones públicas, y llegarán al gobierno con más perspectivas de ejercerlo para beneficio de los ciudadanos y del país al que se deben. Por supuesto, el parque jurásico de la política se opone a la reforma porque esta los deslegitima y debilita, potenciando y fortaleciendo liderazgos democráticos, eficientes y transformadores.

En la prolongada noche de las dictaduras militares latinoamericanas, muchos partidos políticos ejercieron el poder y otros se desarrollaron en la oposición a la dictadura, mientras las fuerzas revolucionarias e insurgentes se convirtieron en partidos políticos después del triunfo de la revolución (Nicaragua) o de los acuerdos de paz fundacionales de la democracia (El Salvador y Guatemala). Muchos de estos partidos enfrentaron, o enfrentan, el desafío de modernizarse y democratizarse, de hacerse más transparentes y de abrirse a diversos sectores de la sociedad. Solo así enfrentarían con mayor éxito la transición de la autocracia a la democracia y contribuirían a su profundización y consolidación.

Desarrollar y mantener estructuras internas democráticas, promover y practicar la transparencia y la rendición de cuentas y revitalizar constantemente su membrecía a través del alcance a nuevos sectores es lo que hacen muchos de los partidos políticos más efectivos. Dentro de estas tres áreas han sido identificadas las mejores prácticas para mejorar consistentemente su desempeño, desarrolladas en el conocido "Triángulo de las mejores prácticas de partidos efectivos", elaborado en y promovido por el Instituto Nacional Demócrata para Asuntos Internacionales (NDI).

En dicha publicación se afirma: "La democracia interna en un partido político está caracterizada por reglas, organización y procesos transparentes, responsables e inclusivos. Cuando se aplican en la práctica, estos ideales abstractos conllevan a beneficios bastante reales a los partidos. Los partidos políticos que se concentran en la transparencia, rendición de cuentas e inclusión, suelen estar mejor organizados y son capaces de encontrar más recursos. Las estructuras más abiertas e inclusivas permiten a los partidos llevar a cabo campañas más efectivas, dinámicas y competitivas, atraer una base más amplia de talentos para el personal y voluntarios, expandir y mejorar el respaldo entre las bases $y$ explorar más recursos humanos y financieros". 


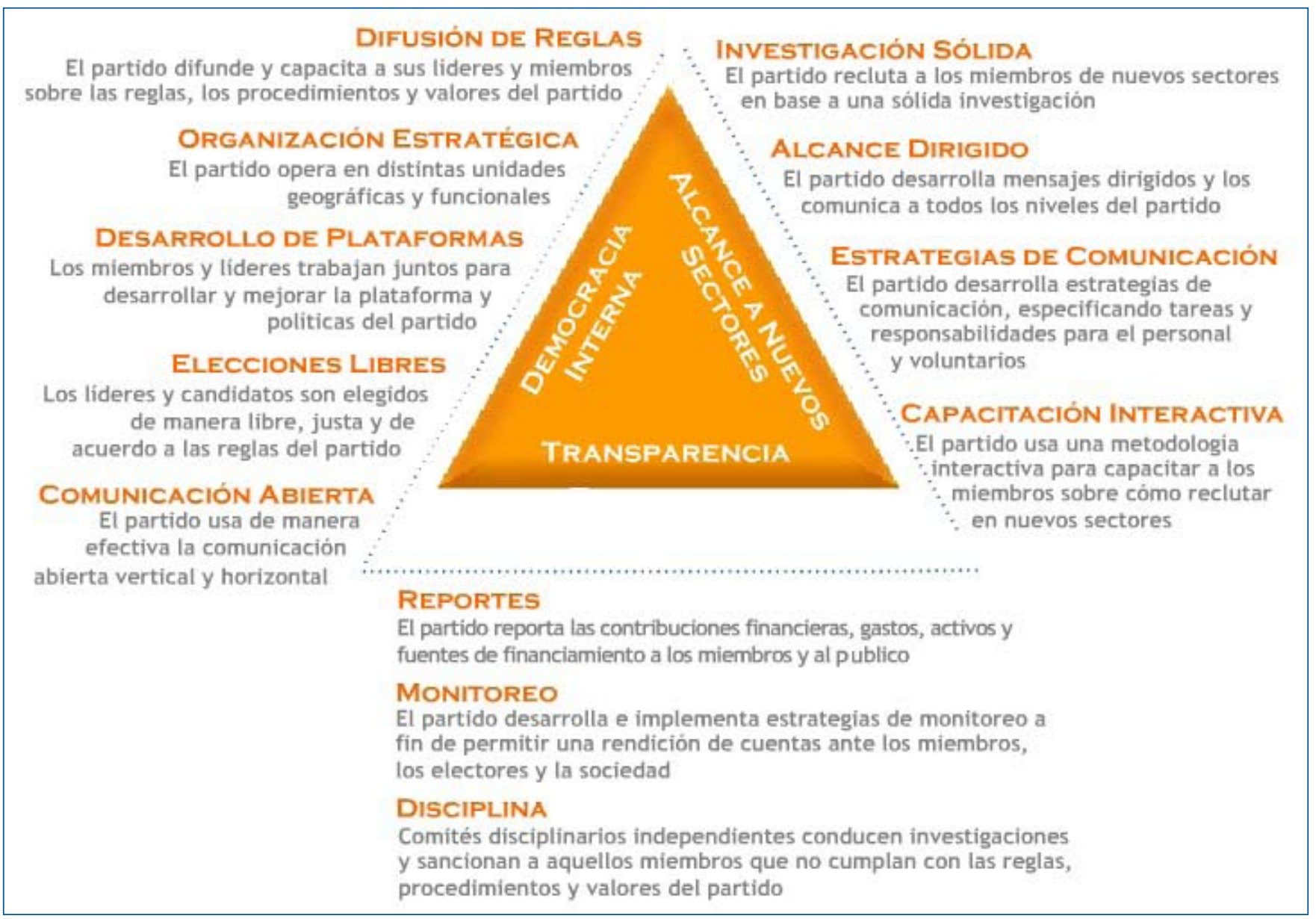

3. El surgimiento y desarrollo de nuevos partidos de los ciudadanos

Si el sistema de partidos políticos es el centro y origen último del problema del sistema democrático-institucional que padecemos, su renovación o refundación es fundamental para la revitalización del sistema democrático. Necesitamos el surgimiento y desarrollo de partidos políticos de ciudadanos vinculados y articulados con movimientos cívico-políticos democrático-progresistas.

Para ver si efectivamente un partido tiene voluntad política renovadora y métodos efectivos para transformarse, hay que analizar si está dispuesto a desarrollar y mantener estructuras internas democráticas, promover y practicar la transparencia y la rendición de cuentas, y revitalizar su membrecía a través del alcance a nuevos sectores.

Además, deberá formular y tener un proyecto de desarrollo nacional (proyecto político, económico y social de mediano y largo plazo) que sea pertinente y realista para el futuro del país, una estrategia política de corto y mediano plazo, una estrategia electoral de mediano y largo plazo, y una estrategia y plan efectivo de desarrollo partidario.

Por proyecto de desarrollo de mediano y largo plazo entendemos una propuesta coherente y realista de transformación y progreso democrático, económico y social para un período de al menos una o dos décadas de duración entendido y asumido por la dirigencia nacional, departa- 
mental y municipal, y transmitido y propuesto a diferentes sectores de la sociedad. Esta es la razón de ser, la pertinencia, del partido.

Por estrategia política entendemos "un conjunto de acciones diseñadas y planificadas sistemáticamente en el tiempo y ejecutadas para lograr un determinado fin. La estrategia política está asociada a la conducción y el liderazgo y al concepto de "inteligencia estratégica: 1. La necesidad de la información como insumo necesario para "clasificar y jerarquizar acontecimientos", y la inteligencia necesaria, pero no suficiente, para adoptar una decisión, con lo cual estamos en presencia de las funciones descriptivas y prescriptivas que concurren a la misma. 2. El valor del fin y propósito como dominante de la concepción y decisión estratégica. 3. Las dimensiones psicológicas y sociológicas de la inteligencia humana, generadora de futuro, consecuente con la visión teleológica, inteligencia estratégica, saber, de naturaleza multidisciplinaria y sistémica, en el cual, necesaria e imprescindiblemente, debe poder apoyarse el conductor estratégico, cualquiera sea su ámbito y nivel, para la formulación de objetivos y políticas coherentes, la selección y adopción de estrategias eficaces, la dirección y supervisión de acciones eficientes, tendientes al logro de una situación deseada, a crear o mantener, en todo tiempo. ${ }^{14}$

Por estrategia electoral entendemos un conjunto de líneas estratégicas y tácticas de organización y comunicaciones modernas, con sus respectivas gestiones de relaciones y financiamiento para maximizar el espacio de apoyo político-electoral y transformarlo en victoria en una serie de eventos electorales. Dicha estrategia parte y es acompañada de estudios de opinión pública especializados para la formulación, seguimiento y evaluación de la estrategia electoral y de asesores especializados en diseño y ejecución de estrategias, campañas, organización y comunicaciones electorales, profesionales/especialistas en éxitos electorales. Dicha estrategia debe formularse y comenzar su ejecución entre 12 y 18 meses antes del evento electoral.

Necesitamos el impulso de partidos democráticos y eficaces, de demócratas capaces, de nuevos liderazgos democráticos, eficientes y transformadores. De partidos políticos de ciudadanos, y de su vinculación y articulación con los movimientos cívico-políticos democrático-progresistas. Sin un movimiento más amplio, más libre y más representativo, el partido no tendría el espacio, la legitimidad y los recursos necesarios para avanzar, posicionarse y elegir, pero sin instrumento político-electoral el movimiento no podrá trasladar su fuerza social en poder.

Los(as) ciudadanos(as) seguiremos teniendo una enorme deuda pendiente que arreglar con la democracia y con la historia, el desarrollo de un amplio movimiento cívico-político que un día logre, después de crear y desarrollar el partido de los ciudadanos, tener una contundente mayoría política y social en el país, en el gobierno y en la asamblea legislativa, que nos permita, finalmente, profundizar y consolidar la democracia constitucional-ciudadana y sacar a nuestra querida patria de la corrupción, la impunidad y el atraso a la que la ha sometido la partidocracia.

14 En Emiliano Augusto "La estrategia política. Desde Heriberto J. Auel”, 17 febrero, 2008. 


\section{Notas finales}

* RESOluCiONES DE LA SALA DE LO CONSTITUCIONAL DE LA CORTE SUPREMA DE JUSTICIA:

\section{Año 2011}

6 de junio: declara inaplicable la reforma al artículo 14 de Ley Orgánica Judicial y admite dos demandas contra la Ley del Presupuesto 2011.

3 de junio: rechaza un amparo contra la prohibición de exportar desperdicios y desechos de fundición; protege a un viudo a quien el Inpep le negó la pensión por no sufrir incapacidad física.

25 de mayo: declara inconstitucional la Comisión Especial investigadora sobre posibles abusos de la Inspectoría General de la Policía Nacional Civil.

19 de mayo: estima vulnerados los derechos de un servidor público que fue despedido de forma improcedente; 19 de mayo del 2011: ampara a una mujer embarazada que fue despedida de su trabajo.

13 de mayo: declara inconstitucional la elección de los magistrados del TSE Julio Eduardo Moreno Niños y Óscar Morales Herrera.

29 de abril: declara improcedente la pretensión contenida en la demanda a la Asamblea Legistaliva por la elección de los últimos cinco magistrados de la Corte Suprema de Justicia.

29 de abril: inconstitucionalidad del salvataje a los partidos políticos PDC y PCN en la elección del año 2004.

15 de abril: sentencia caso contra la Corte Suprema de Justicia en pleno por el despido del señor Hugo Salvador Zelaya Monteagudo; Auditoría judicial reconoce labor de jueza en casos del exministro de Salud y de la pareja acusada de lavado por \$ 818.000; Sala de lo Constitucional rechaza declarar inconstitu- cional la falta de regulación de los casos específicos en que se podría admitir un aborto.

18 de marzo: ampara en herencia a hijo nacido fuera del matrimonio

4 de marzo: restablece que no se divulguen los datos personales sin autorización

10 de febrero: Sala de lo Constitucional avala responsabilidad patrimonial del ISSS por mala praxis; declara Inadmisible la demanda de inconstitucionalidad de la Ley de Fideicomisos de Obligaciones Previsionales; declara inadmisible demanda contra ascenso del ministro de Defensa

\section{Año 2010}

24 de septiembre: Declara inconstitucional el Art. 191 del Código Penal vigente sobre la libertad de expresión.

25 de agosto: Declara inconstitucional los Art. 2 y 6 de la Ley de Presupuesto para el ejercicio financiero fiscal 2010, que permite a la presidencia de la República hacer transferencias discrecionales de una institución pública a otra.

29 de julio: declara inconstitucional varios artículos del Código Electoral, abriendo la posibilidad a las candidaturas independientes y a las listas abiertas de candidatos a diputados.

** "Democracia constitucional es el término acuñado por autores como Karl Friedrich Krause y Karl Loewenstein, que han difundido este término para referirse a aquellas democracias que se fundan sobre una Constitución con un contenido particular, substancial. Esto y más, tiene su explicación en que la palabra democracia es utilizada por los más opuestos sectores políticos, por lo que se ha creado una confusión en cuanto a su significado, lo que hace necesario un esfuerzo para precisar su sentido y alcance; de allí surge el concepto elaborado por los autores ya citados. La Democracia Constitucional tiene las siguientes características o elementos: Participación política, De- 
rechos fundamentales, Pluralismo político, Principio mayoritario, Separación orgánica de funciones, Representación política. “Para que un régimen sea democrático, debe asegurar cuantitativa y cualitativamente la participación en los asuntos públicos del mayor número posible de personas" (Marcel Prelot, La Ciencia Política, 1965).

"Al no haber jamás coincidencia entre el número de miembros de la población y el número de participantes en asuntos del Estado, pues siempre habrá incapaces, menores de edad o indignos, la lógica democrática tiende a otorgar la participación política más amplia posible. En la democracia representativa esta participación política se expresa en el sufragio universal, la posibilidad de ser elegido en cargos públicos y el acceso a los partidos políticos. En la democracia semidirecta se expresa en las instituciones propias de este sistema, como por ejemplo, el referéndum, plebiscito, revocatoria. El sufragio universal supone el otorgamiento de este derecho a toda la población adulta, sin ninguna exclusión colectiva, sino solo exclusiones individuales y que se es- tablezcan por incapacidades 0 indignidades manifiestas. La Democracia también implica la existencia de libertades e igualdades. Por ello se hace necesario reconocer, regular y garantizar un conjunto de derechos fundamentales o esenciales e inherentes en la persona humana. Por ejemplo, el derecho a la vida, a la libertad personal, a la seguridad individual, que garantiza a toda persona el no ser detenido sino en las condiciones fijadas por la ley y según las formalidades por ella establecidas. También juegan un papel importante la libertad de opinión, de conciencia, de culto y de enseñanza, la libertad o derecho de propiedad, la libertad de emprender o desarrollar cualquier actividad económica. Se comprenden aquí, también, el conjunto de derechos económicos y sociales; los derechos políticos y las igualdades. "La esencia de la democracia constitucional es que los grupos pluralistas más diversos pueden participar ilimitadamente en el proceso económico y político. Todas las fuerzas sociales de importancia tienen garantizada la libertad de competir en un circuito abierto de valores" (Karl Loewenstein, Teoría de la Constitución, 1970. Tomado de Wilkipedia). 